\title{
PENGARUH MODEL QUANTUM LEARNING TERHADAP PENGUASAAN TEKNIK DASAR LOMPAT JAUH SISWA PADA PEMBELAJARAN ATLETIK DI SEKOLAH DASAR
}

\author{
Prayogi Nurfauzan \\ Universitas Negeri Semarang \\ Email: prayoginurfauzan99@yahoo.com
}

Naskah diterima : 2 Oktober 2018, direvisi : 6 Oktober 2018, disetujui : 21 Oktober 2018

\begin{abstract}
The purpose of research is to find out quantum effect on mastery learning basic techniques long jump elementary school students. The study was conducted in the 2 nd half of the fourth grade students at State Elementary School of Nangela in Bandung. The research sample of 20 students from each of the experimental group and the control group. During the research process, the experimental group was given quantum learning, while the control group was given conventional learning. The research approach used is quantitative approach with quasi experimental method nonequivalent groups design pretest-posttests. Data analysis was performed using t-test. The significance level of 0.05 . The results showed a significant difference between students' mathematical reasoning scores of the experimental group and the control group.
\end{abstract}

Keywords: Quantum Learning, Mastery of Basic Technique Long Jump, Class IV, Elementary School.

Pengutipan: Prayogi Nurfauzan. (2018). Pengarub Model Quantum Learning terhadap Penguasaan Teknik Dasar Lompat Jauh Siswa pada Pembelajaran Atletik di Sekolah Dasar. JMIE: Journal of Madrasah Ibtidaiyah Education, 2(2), 2018, 254-264. jmie.v2i2.77.

Permalink/DOI: http://dx.doi.org/ 10.32934/jmie.v2i2.77 


\section{PENDAHULUAN}

Pendidikan merupakan salah satu faktor utama dalam mempengaruhi kemajuan suatu negara, karena pendidikan dituntut untuk dapat mengembangkan dan meningkatkan sumber daya manusia dalam suatu negara. Hal ini diperkuat dengan adanya penjelasan mengenai pengertian pendidikan menurut Undang-undang Sistem Pendidikan Nasional No. 20 tahun 2003 (Tim Fokusmedia, 2009: 2) yang menyatakan bahwa "Pendidikan adalah suatu usaha sadar dan terencana untuk mewujudkan suasana belajar dan proses pembelajaran agar peserta didik secara aktif mengembangkan potensi dirinya untuk memiliki kekuatan spiritual keagamaan, pengendaliandiri, kepribadian, kecerdasan, akhlak mulia, serta keterampilan yang diperlukan dirinya, masyarakat, bangsa dan negara".

Melalui program pendidikan akan mengubah sikap dan tata laku masyarakat menjadi sosok manusia yang dewasa dalam menyelesaikan berbagai masalah, baik masalah pribadi, keluarga, masyarakat maupun bangsa dan negara. Selain itu, berdasarkan Undang-undang Sistem Pendidikan Nasional No. 20 tahun 2003 pasal 4 ayat 4 (Tim Fokusmedia, 2009:6) telah dijelaskan bahwa "Pendidikan diselenggarakan dengan memberikan keteladanan, membangun kemauan, dan mengembangkan kreativitas peserta didik dalam proses pembelajaran”.

Untuk mewujudkan tujuan pendidikan nasional yang diharapkan, maka disusunlah suatu kurikulum yang dapat dijadikan sebagai program pendidikan yang direncanakan secara sistematik mengemban peranan yang sangat penting bagi pendidikan para siswa. Kurikulum pendidikan dasar dikembangkan sesuai dengan tingkat perkembangan dan minat serta kebutuhan siswa sekolah dasar (SD). Dimana kurikulum pendidikan dasar ini harus dapat menjadikan pendidikan sebagai wahana untuk meningkatkan kecerdasan dan potensi-potensi yang dimiliki siswa SD. Isi kurikulum pendidikan dasar merupakan susunan bahan kajian dan mata pelajaran untuk mencapai tujuan pendidikan dasar secara nasional (Sagala, 2009:234).

Dalam Peraturan Menteri No 23 Tahun 2006 tentang Standar Kompetensi Lulusan untuk Satuan Pendidikan Dasar dan Menengah (Depdiknas, 2008:10), telah dijelaskan bahwa salah satu mata pelajaran yang wajib dibelajarkan di sekolah dasar yaitu mata pelajaran Pendidikan Jasmani, Olahraga dan Kesehatan (PJOK). Dimana pada hakikatnya, Pendidikan Jasmani, Olahraga dan Kesehatan merupakan bagian integral dari pendidikan secara keseluruhan, bertujuan untuk mengembangkan aspek kebugaran jasmani, keterampilan gerak, keterampilan berfikir kritis, keterampilan sosial, penalaran, stabilitas emosional, tindakan moral, aspek pola hidup sehat dan pengenalan 
lingkukangn bersih melalui aktivitas jasmani, olahraga, dan kesehatan terpilih yang direncanakan secara sistematis dalam rangka mencapai tujuan pendidikan nasional.

Pendidikan sebagai suatu proses pembinaan manusia yang berlangsung seumur hidup, pendidikan jasmani, olahraga, dan kesehatan yang diajarkan di sekolah memiliki peranan sangat penting, yaitu memberikan kesempatan kepada perserta didik unuk terlibat langsung dalam berbagai pengalaman belajar melalui aktivitas jasmani, olahraga, dan keseharan yang terpilih yang dilakukan secara sistematis. Pembekalan pengalaman belajar itu diarahkan untuk membina pertumbuhan fisik dan pengembangan psikis yang lebih baik, sekaligus membentukan pola hidup sehat dan bugar sepanjang hayat.

Dalam sebuah proses pembelajaran perlu di tetapkan terlebih dahulu suatu perencanaan yang matang agar tercipta suatu hasil yang optimal terhadap peserta didik. Perencanaan merupakan ketetapan suatu tujuan, memilih kegiatan untuk tercapainya tujuan tersebut dan mengalokasikan sumber-sember pada setiap kegiatan. Terutama tujuannya dalam bidang keolahragan atau pendidikan jasmani terhadap peserta didik dalam peningkatan kualitas fisik, mental, spiritual dan pengetahuan mengenai bidang tersebut, sesuai dengan pengertian pendidikan jasmani adalah suatu proses pembelajaran yang didesain untuk meningkatan kebugaran jasmani, mengembangkan keterampilan motorik, pengetahuan dan perilaku hidup aktif, dan sikap sportif melakukan kegiatan jasmani (Juniar, 2012:21).

Selain itu, dalam peroses pembelajaran juga perlu memperhatikan model, metode dan media yang akan di berikan ke peserta didik agar anak-anak memiliki rasa senang dalam belajar dan juga supaya bisa meningkatan motivasi anak belajar. Sekolah dasar merupakan salah satu jenjang pendidikan yang membelajarkan konsep lompat jauh kepada anak. Untuk mulai memperkenalkan olahraga lompat jauh pada anak-anak, Syarifuddin (Lirnawati, 2014) mengungkapkan bahwa lompat jauh merupakan salah satu nomer lompat dari cabang olahraga atletik yang paling populer dan paling sering di perlombakan dalam kompetisi kelas dunia, termasuk Olimpiade. Lompat jauh adalah suatu gerakan melompat kedepan atas dalam upaya membawa titik berat badan selama mungkin di udara (melayang di udara) yang di lakukan dengan cepat dan dengan jalan melakukan tolakan pada dua kaki untuk mencapai jarak yang sejauh-jauhnya.

Atletik adalah gabungan dari beberapa jenis olahraga yang secara garis besar datap di kelompokan menjadi lari, lempar,dan lompat. Kata ini berasal dari Yunani "athlon" yang berarti "kontes". Atletik merupakan cabang olahraga yang diperlombakan pada olimpiade pertama pada 776 SM. Induk organin sasi olahraga atletik di Indonesia PASI (Persatuan Atletik Seluruh Indonesia). Nomer - nomer atletik terdiri dari nomer 
lari, nomer lempar, dan nomer lompat. Pengertian nomer lari yaitu lari adalah gerakan melangkah dengan kecepatan tinggi. Sedangkan perbedaan lari dengan jalan adalah pada saat jalan salah satu kaki selalu berhubungan dengan tanah sedangkan pada saat lari ada saatnya tubuh melayang di udara atau tiadak menyentuh tanah. Perbedaan lari dan berjalan, saat berjalan kaki kiri melangkah dan menapak tanah, baru kaki kana melangkah dan menapak tanah. Terus berulang-ulang tanpa ada kesempatan kedua kaki tidak menapak tanah (gerakan melayang). Saat berlari kaki kiri melangkah, sebelum kaki kiri menapak tanah, kaki kana mendorong tanah dan terjadi gerakan melayang sebentar. Lalu kaki kiri menapak dan sebelum kaki kanan menapak, kaki kiri telah melakukan gerakan mendorong juga.

Lompat jauh merupakan salah satu nomer lompat selain lompat jangkit, lompat tinggi, dan lompat galah. Tujuan lompat jauh adalah melompat sejauh-jauhnya dengan memindahkan seluruh tubuh dari titik-titik tertentu ke titik lainnya, dengan cara berlari secepat-cepatnya kemudian menolak, melayang di udara dan mendarat, pencapaian jarak lompatan yang sejauh-jauhnya. Untuk mencapai jarak lompat yang jauh, terlebih dahulu pelompat harus memahami unsur-unsur poko pada lompat jauh. Teknik lompat jauh dapat dibagi sebagian berikut: (1) Awalan atau acang-acang, (2) Tumpuan atau tolakan, (3) Melayang di udara, dan (4) Mendarat di bak pasir.

Berdasarkan pengalaman peneliti dalam mengajar di SDN Nangela Kecamatan Paseh Kabupaten Bandung, masih terdapat siswa yang kurang mampu melakuan teknik lompat jauh secara benar, terutama ketika siswa melakukan fase melayang dan pendaratan. Selain itu masih terdapat siswa yang masih kurang berani dalam melakukan lompat jauh. Untuk mengatasi permasalahan tersebut, salah satu aternatif pemecahan masalahnya yaitu melalui pembelajaran quantum learning. Jika kalau pembelajaran ini tidak dirubah menjadi pembelajaran yang menyenangkan bagi siswa, maka akan mengakibatkan motivasi belajar siswanya rendah, takut untuk mencoba melakukan praktek lompat jauh, dan melakukan teknik lompat jauh yang kurang baik.

Dalam pembelajaran atletik di sekolah dasar, diperlukan suatu model pembelajaran yang menyenangkan supaya siswa tidak merasa takut dalam melakukan lompat jauh. Salah satu model yang dapat dijadikan alternatif dalam pembelajaran atletik adalah model quantum learning. Model quantum learning lebih mengedepankan penciptaan suasana belajar yang lebih menyenangkan, pandangan positif terhadap objek yang dipelajari, musik, dan suasana bermain yang tidak kaku De Porter dan Hermacki Kaifa (2012:75). 
Model quantum learning merupakan suatu desain pembelajaran yang dapat mempertajam pemahaman dan daya ingat siswa, serta membuat belajar sebagai suatu proses yang menyenangkan dan bermanfaat. Quantum Learning menjadikan mengajar dan belajar menjadi senang dengan peningkatan 'Aha' pada kegiatan penemuan. Ini membantu guru menampilkan isi mereka yang merupakan sebuah jalan yang dapat menyertakan dan memberdayakan siswa. Model ini juga memadukan belajar dan kecakapan hidup, menghasilkan siswa-siswa sebagai pebelajar yang efektif selamanya bertanggungjawab bagi pendidikannya sendiri De Porter dan Hermacki (2012:56)

Terdapat beberapa penelitian sebelumnya mengenai model quantum learning. Pada tahun 2010, Agus Rahman melaksanakan penelitian di SDN Cijati II Kecamatan Cileunyi Kabupaten Bandung yang menghasilkan bahwa penggunaan pendekatan quantum learning dapat meningkatkan kecerdasan kinestetik dan hasil belajar siswa kelas IV sekolah dasar. Pada tahun 2013, Dodong Wiganda melaksanakan penelitian di SDN Nangela Kecamatan Paseh Kabupaten Bandung yang menghasilkan bahwa model quantum learning dapat meningkatan aktivitas dan respon siswa dalam pembelajaran akuatik di kelas I sekolah dasar. Dalam hal penelitian ini, model quantum learning diterapkan dalam rangka peningkatan pehamanan dan keterampilan gerak dasar lompat jauh pada pembelajaran atletik di SD.

Dari latar belakang dan masalah yang sudah dipaparkan sebelumnya, maka penulis mesara penting untuk meneliti permasalahan-permasalahan tersebut, oleh karena itu penulis bermaksud mengadakan penelitian dengan judul "Pengaruh Model Quantum Learning terhadap Penguasaan Teknik Dasar Lompat Jauh Siswa pada Pembelajaran Atletik di Sekolah Dasar".

\section{METODE PENELITIAN}

Pendekatan penelitian yang digunakan yaitu pendekatan kuantitatif, hal tersebut dikarenakan penelitian ini mengontrol bagaimana kelompok subjek penelitian diperlakukan dan kemudian mengukur bagaimana tindakan mempengaruhi setiap kelompok, sehingga diperlukan penelitian kuantitatif. Metode yang digunakan dalam penelitian ini adalah eksperimen kuasi, hal ini dikarenakan penelitian dilaksanakan dengan maksud untuk mempelajari sesuatu dengan mengubah suatu kondisi dan mengamati pengaruhnya terhadap hal lain. Penelitian eksperimen kuasi yang akan dilaksanakan yaitu dengan bentuk nonequivalent groups pretest-posttets design yang mengacu kepada pendapat Fraenkel dan Wallen (2007:278). Populasi dalam penelitian ini adalah seluruh siswa kelas IV SDN Nangela Kecamatan Paseh Kabupaten Bandung 


\section{HASIL PENELITIAN DAN PEMBAHASAN}

Model quantum learning yang dilaksanakan pada penelitian ini dengan pengimplementasian tahapan-tahapan yang dirancang oleh De Porter yaitu tahap TANDUR (tumbuhkan, alami, namai, demonstrasikan, ulangi, rayakan). Tahapantahapan model quantum learning ini dilaksanakan oleh guru bersama siswa secara bertahap dari tahap tumbuhkan sampai tahap perayaan.

Berdasarkan hasil pelaksanaan model quantum learning, dapat diketahui bahwa siswa sangat senang dan bahagia sekali dalam melaksanakan setiap tahapan model quantum learning, di mana motivasi siswa dalam belajar berkembang secara baik, mereka pun sangat yang semangat dan menyenangkan belajar yang diiringi instrumen musik. Mereka pun sangat senang mengakhiri pembelajaran dengan melakukan perayaan.

Hasil pelaksanaan model quantum learning dalam meningkatkan penguasaan teknik lompat jauh siswa dapat terlihat dari hasil tes penguasaan teknik lompat jauh siswa yang dibuat dengan menggunakan instumen tes praktek penguasaan teknik lompat jauh siswa. Indikator yang dijadikan kriteria dalam penyekoran penguasaan teknik lompat jauh siswa pada penelitian ini yaitu dengan mengukur kemampuan siswa dalam melakukan awalan, tolakan, melayang dan pendaratan.

Secara umum hasil tes penguasaan teknik lompat jauh siswa dapat dilihat pada Tabel 1. berikut:

Tabel 1. Hasil Tes Penguasaan Teknik Lompat Jauh Siswa

\begin{tabular}{ccccc}
\hline Kelompok & Periode Tes & Rata-Rata & Varians & Simpangan Baku \\
\hline \multirow{2}{*}{ Eksperimen } & Pretest & 50,36 & 39,211 & 6,262 \\
& Postest & 81,45 & 55,815 & 7,471 \\
\multirow{2}{*}{ Kontrol } & Pretest & 50,69 & 38,380 & 6,195 \\
& Postest & 70,53 & 55,054 & 7,420 \\
\hline
\end{tabular}

Berdasarkan tabel 1. maka dapat diketahui peningkatan rata-rata penguasaan teknik lompat jauh siswa kelompok eksperimen yaitu 31,09, sedangkan peningkatan rata-rata penguasaan teknik lompat jauh siswa kelompok kontrol lebih rendah yaitu sebesar 19,84. Hal ini menunjukkan bahwa rata-rata peningkatan penguasaan teknik lompat jauh siswa kelompok eksperimen yang menggunakan model quantum learning lebih baik daripada rata-rata peningkatan penguasaan teknik lompat jauh siswa kelompok kontrol yang menggunakan pembelajaran konvensional. 
Berdasarkan hasil penelitian, model quantum learning terbukti lebih berpengaruh secara signifikan terhadap penguasaan teknik lompat jauh siswa daripada pembelajaran konvensional, hasil analisis data penguasaan teknik lompat jauh siswa menunjukkan adanya perbedaan yang signifikan antara skor penguasaan teknik lompat jauh siswa dari kelompok eksperimen dengan kelompok kontrol.

Hasil skor penguasaan teknik lompat jauh siswa pada pembelajaran lompat jauh dapat tergambar pada grafik 1 . berikut ini.

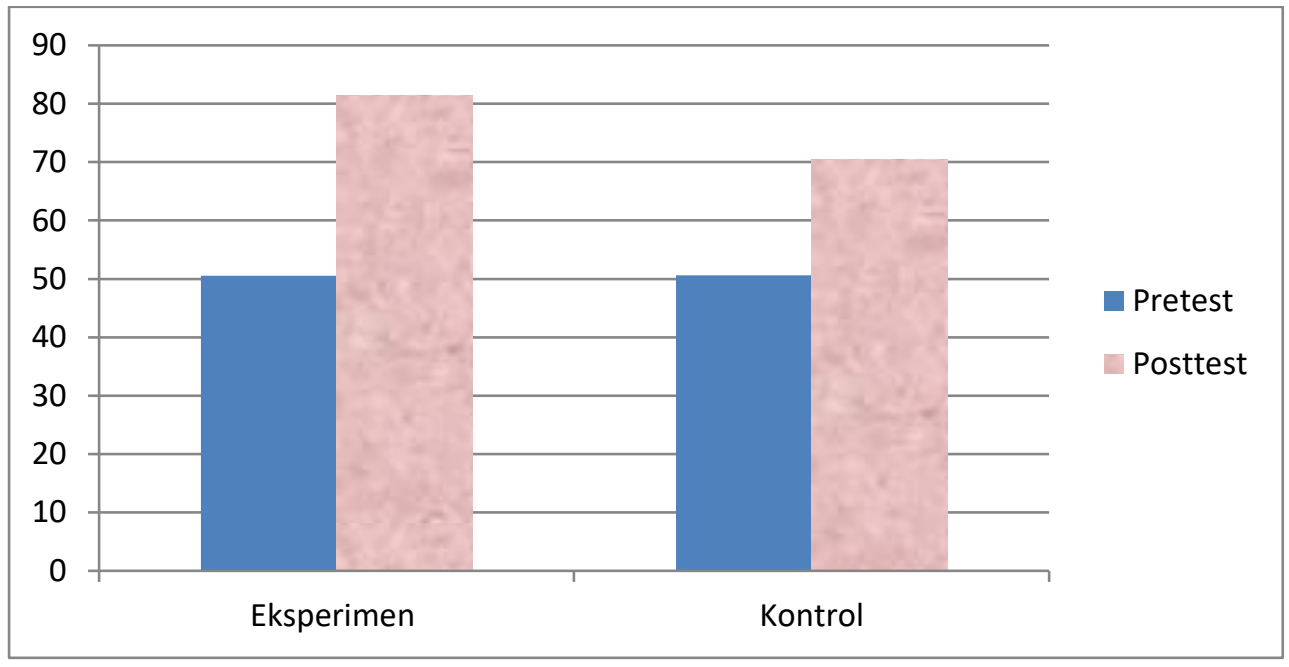

Grafik 1. Hasil Skor Penguasaan Teknik Lompat Jauh Siswa

Berdasarkan grafik 1. di atas, dapat diketahui bahwa nilai rata-rata penguasaan teknik lompat jauh siswa kelompok eksperimen mengalami peningkatan sebesar 30,85, di mana pada saat pretest memperoleh rata-rata sebesar 50,52, sedangkan pada saat posttest mengalami peningkatan rata-rata penguasaan teknik lompat jauh siswa kelompok eksperimen menjadi 81,37. Sedangkan rata-rata nilai akhir posttest penguasaan teknik lompat jauh siswa kelompok kontrol mengalami peningkatan sebesar 19,81, di mana rata-rata nilai akhir pretest penguasaan teknik lompat jauh siswa kelompok kontrol yaitu 50,64, sedangkan rata-rata nilai akhir posttest penguasaan teknik lompat jauh siswa kelompok kontrol yaitu 70,45.

Selain mengalami peningkatan penguasaan teknik lompat jauh siswa, terdapat perbedaan yang signifikan antara penguasaan teknik lompat jauh siswa kelompok eksperimen yang menggunakan model quantum learning dengan penguasaan teknik lompat jauh siswa kelompok kontrol yang menggunakan pembelajaran konvensional. Langkah awal dalam pengujian perbedaan rerata antara kedua kelompok yaitu dengan 
cara uji-t hasil pretes penguasaan teknik lompat jauh siswa. Di mana hasil uji-t penguasaan teknik lompat jauh siswa pada saat pretest yaitu bahwa nilai signifikansi (Pvalue) untuk faktor pembelajaran sebesar $0,800 \geq 0,05$ maka $\mathrm{H}_{0}$ diterima. Dengan kata lain, tidak terdapat perbedaan rerata skor pretest penguasaan teknik lompat jauh siswa antara kelompok kontrol dan kelompok eksperimen berdasarkan faktor pembelajaran. Akan tetapi, hasil uji perbedaan rerata posttest penguasaan teknik lompat jauh siswa yaitu bahwa nilai signifikansi (P-value) untuk faktor pembelajaran sebesar 0,000<0,05 maka $\mathrm{H}_{0}$ ditolak. Dengan kata lain, terdapat perbedaan rerata skor posttest penguasaan teknik lompat jauh siswa antara kelompok eksperimen dengan kelompok kontrol. Adapun hasil perhitungan uji perbedaan rerata dapat dilihat pada Tabel 2. berikut ini.

Tabel 2. Hasil Tes Penguasaan Teknik Lompat Jauh Siswa

\begin{tabular}{ccc}
\hline Tes & Pembelajaran & Perbedaan \\
\hline Pretest & Eksperimen $\begin{array}{c}\text { (Quantum Learning) - Kontrol } \\
\text { (Konvensional) }\end{array}$ & $50,52<50,64$ \\
Posttest & Eksperimen $\begin{array}{c}\text { (Quantum Learning) }- \text { Kontrol } \\
\text { (Konvensional) })\end{array}$ & $81,37>70,45$ \\
\hline
\end{tabular}

Berdasarkan hasil rerata kelompok eksperimen dan kelompok kontrol tersebut, maka dapat diketahui bahwa hasil posttest antara kelompok eksperimen dengan kelompok kontrol memiliki perbedaan, di mana rata-rata hasil penguasaan teknik lompat jauh siswa lebih besar di kelompok eksperimen yaitu dengan menggunakan model quantum learning. Sehingga dapat diketahui bahwa model quantum learning lebih berpengaruh secara signifikan terhadap penguasaan teknik lompat jauh siswa daripada pembelajaran konvensional. Hal ini ditandai dari rata-rata nilai akhir posttest penguasaan teknik lompat jauh siswa kelompok eksperimen lebih besar 10,92 dibandingkan dengan kelompok kontrol, di mana rata-rata nilai akhir posttest penguasaan teknik lompat jauh siswa kelompok eksperimen yaitu 81,37, sedangkan rata-rata nilai akhir posttest penguasaan teknik lompat jauh siswa kelompok kontrol yaitu 70,45.

Berdasarkan pemaparan di atas, dapat disimpulkan model quantum leraning lebih berpengaruh terhadap penguasaan teknik lompat jauh siswa pada pembelajaran atletik di kelas IV sekolah dasar. Efektivitas model model quantum leraning terhadap penguasaan teknik lompat jauh siswa dikarenakan pembelajaran dengan menggunakan model quantum leraning membuat siswa belajar lebih menyenangkan. Hal ini senada dengan pendapat Harmono (2017) yang menjelaskan bahwa model quantum leraning merupakan 
suatu proses pembelajaran dengan menyediakan latar belakang dan strategi untuk meningkatkan proses belajar mengajar dan membuat proses tersebut menjadi lebih menyenangkan.

Model quantum leraning terbukti mampu meningkatkan proses pembelajaran lompat jauh siswa. Hal ini ditemukan ketika pembelajaran, siswa merasa senang belajar sampai lupa waktu, mereka tidak mau berhenti belajar dengan menggunakan model quantum leraning ini. Siswa Nampak aktif dalam pembelajaran, tidak mengobrol atau malas-malasan, serta tampak keterampilan siswa dalam teknik lompat jauhpun mengalami peningkatkan yang signifikan. tentu hal tersebut dibuktikan dari hasil pengujian hipotesis yang menunjukkan bahawa model quantum leraning lebih berpengaruh terhadap penguasaan teknik lompat jauh siswa pada pembelajaran atletik di kelas IV sekolah dasar. Hal ini senada dengan hasil penelitian Nurjanah (2016) yang menghasilkan Model belajar quantum learning terbukti mampu meningkatkan proses pembelajaran dan berdampak pada perbaikan proses belajar siswa dan menjadi kan guru menjadi percaya diri.

Hasil penelitian dan pembahasan berbagai hasil penelitian terdahulu yang menunjukkan bahwa model quantum learning terbukti efektif dalam peningkatan kualitas pembelajaran, sehingga penguasaan teknik lompat jauh siswa pun dapat meningkat dengan baik. Oleh karena itu, model quantum learning ini dapat dijadikan salah satu alternatif yang dapat digunakan guru untuk memperbaiki kualitas pembelajaran di kelas, dan meningkatkan penguasaan serta hasil belajar siswa.

\section{KESIMPULAN}

Sejalan dengan rumusan masalah dan pertanyaan penelitian, studi ini memperoleh kesimpulan yang berkenaan dengan hasil studi empirik tentang eksperimen pengaruh model quantum learning terhadap penguasaan teknik lompat jauh siswa pada pembelajaran atletik di kelas IV sekolah dasar. Berdasarkan hasil penelitian yang diperoleh, maka dapat diambil kesimpulan sebagai berikut.

Pertama, model quantum learning berpengaruh signifikan terhadap penguasaan teknik lompat jauh siswa pada pembelajaran atletik di kelas IV sekolah dasar. Hal ini ditandai dari hasil pengujiann hipotesis yang menunjukkan nilai signifikansi (P-value) untuk faktor pembelajaran sebesar 0,000 lebih kecil dari 0,05 maka $\mathrm{H}_{0}$ ditolak. Dengan kata lain, terdapat perbedaan rerata skor pretest dan posttest penguasaan teknik lompat jauh siswa kelompok eksperimen yang menggunakan model quantum learning. 
Kedua, model quantum learning lebih berpengaruh secara signifikan terhadap penguasaan teknik lompat jauh siswa daripada pembelajaran konvensional. Hal ini ditandai dari rata-rata nilai akhir posttest penguasaan teknik lompat jauh siswa kelompok eksperimen lebih besar 10,92 dibandingkan dengan kelompok kontrol, di mana rata-rata nilai akhir posttest penguasaan teknik lompat jauh siswa kelompok eksperimen yaitu 81,37, sedangkan rata-rata nilai akhir posttest penguasaan teknik lompat jauh siswa kelompok eksperimen 2 yaitu 70,45. Selain itu, hasil pengujian hipotesis menunjukkan bahwa terdapat perbedaan antara skor penguasaan teknik lompat jauh siswa kelompok eksperimen yang menggunakan model quantum learning dengan siswa kelompok kontrol yang menggunakan pembelajaran konvensional.

\section{DAFTAR PUSTAKA}

Depdiknas. (2008). Standar Kompetensi dan Kompetensi Dasar Tingkat SD/MI. Jakarta: Depdiknas.

De Porter, B. \& Hemacki, M. (2012). Quantum Learning: Membiasakan Belajar Nyaman dan Menyenangkan. Bandung: Kaifa.

De Porter, B., Reardon, M., \& Nourie, S. S. (2015). Quantum Teaching: Mempraktekkan Quantum Learning di Ruang - Ruang Kelas. Bandung: Kaifa.

Fraenkel, J. R. dan Wallen, N. E. (2007). How to Design and Evaluate Research in Education. New York: Mcgraw hill.

Harmono, S. (2017). Pengaruh Model Pembelajaran Quantum dan Gaya Belajar Terhadap Pemahaman Konseptual dan Ketrampilan Gerak Pada Mata Pelajaran Pendidikan Jasmani Olahraga dan Kesehatan Siswa Sma Kota Kediri. Jurnal Pembelajaran Olahraga. Vol 3. (No. 1). Hal. 103-114.

Juniar, D. T. (2012). Perencanaan Pembelajaran Olabraga. [online]. Tersedia: http:/ / dickytj.blogspot.co.id/2012/03/v-behaviorurldefaultvmlo.html. Januari 2018]

Lirnawati, Y. (2010). Pengarub Metode Keseluruban dan Metode Bagian Terhadap Hasil Pembelajaran Lompat Jaub Kelas VII di SMP Negeri 1 W arungkondang. Skripsi Sarjana pada FPOK UPI Bandung: tidak diterbitkan. 
Nurjanah (2016). Implementasi Model Belajar Quantum Learning dalam Pembelajaran Berbasis Kearifan Lokal Dikelas IV SDN 110/Iv Kota Jambi. Jurnal Pendidikan Tematik Dikdas Universitas Jambi. Vol 1 (No. 1). Hal. 1-6.

Rahman, A. (2010). Pendekatan Quantum Teaching untuk Meningkatkan Kecerdasan Kinestetik Siswa Melalui Pembelajaran IPS SD Kelas IV. Skripsi Sarjana pada FIP UPI Bandung: tidak diterbitkan.

Sagala, S. (2009). Konsep dan Makna Pembelajaran. Bandung: Alfabeta.

Tim Fokusmedia. (2009). Undang-undang SISDIKNAS (Sistem Pendidikan Nasional). Bandung: Fokusmedia.

Tim PLPG UPI. (2011). Bahan Ajar Pendidikan Jasmani. Bandung: UPI.

Wiganda, D. (2013). Implementasi Model Quantum Learning pada Pembelajaran Akuatik Siswa Kelas ISekolah Dasar. PTK SDN Nangela UPTD Paseh Kab. Bandung: tidak diterbitkan. 